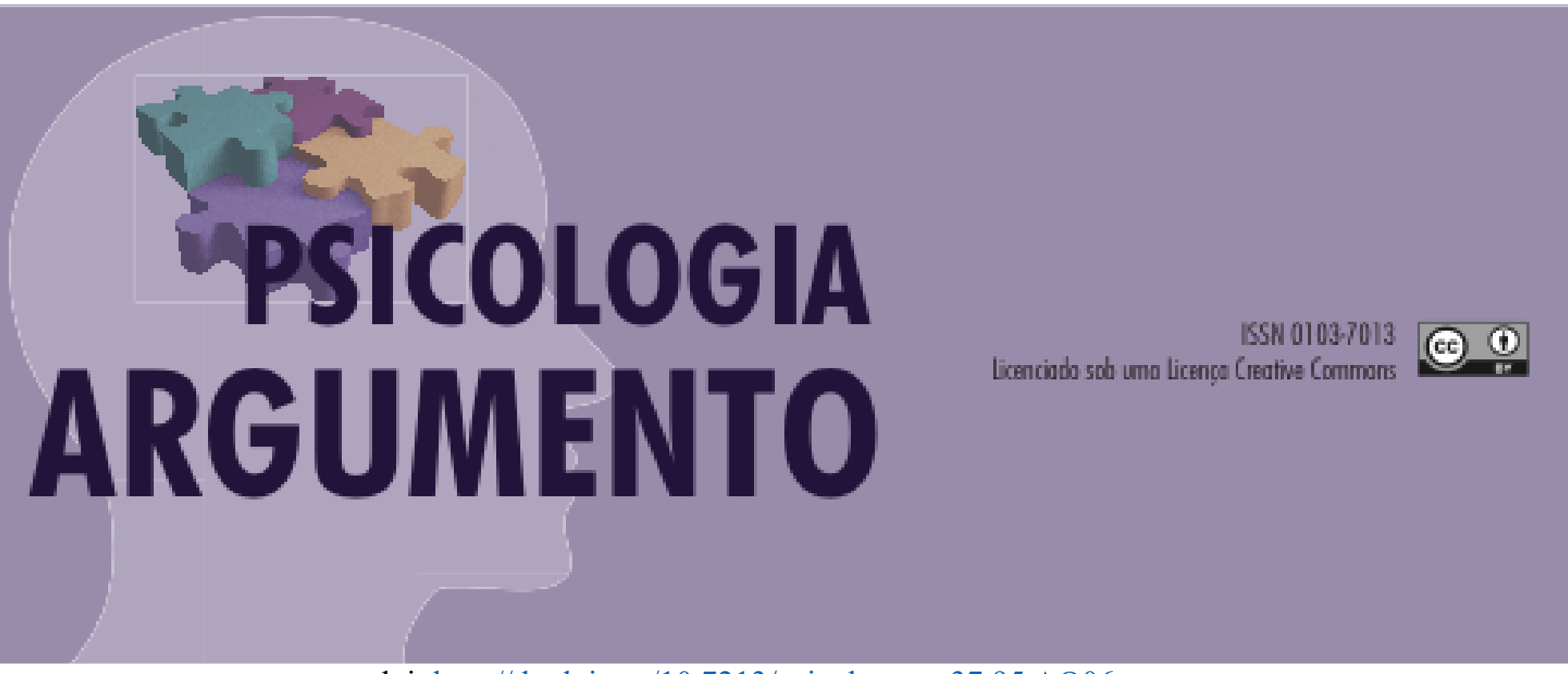

doi: http://dx.doi.org/10.7213/psicolargum.37.95.AO06

\title{
Déficits cognitivos entre crianças em idade escolar com transtornos de aprendizagem: revisão de publicações nacionais
}

Cognitive deficits among school-aged children with learning disorders: review of national publications

Déficit cognitivo en niños en edad escolar con trastornos del aprendizaje: revisión de publicaciones nacionales

Renata Dutra de Oliveira Teixeira

https://orcid.org/0000-0002-7216-8991

Terapeuta ocupacional da Associação Brasileira Beneficente de Reabilitação - ABBR, Rio de Janeiro / RJ. renatadutra.to@gmail.com

Leonardo Valesi Valente

https://orcid.org/0000-0002-0169-8143

Terapeuta ocupacional, especialização em Neuropsicologia, mestrado em Neurologia, professor do Instituto Federal de Educação, Ciência e Tecnologia do Rio de Janeiro -

IFRJ, campus Realengo, Rio de Janeiro / RJ. leonardo.valente@ifrj.edu.br

\section{Resumo}

Complexas alterações cognitivas manifestam-se entre crianças em fase escolar, acarretando dificuldades à leitura, à escrita, ao brincar e à aprendizagem, comprometendo desempenho escolar, desenvolvimento infantil e participação em inserções cotidianas. Esta revisão de literatura visa identificar quais funções cognitivas estão mais prejudicadas entre crianças brasileiras, em idade escolar, que apresentem transtornos de aprendizagem. Realizou-se identificação de estudos nas bases de dados: Literatura Latino-Americana e do Caribe em Ciências da Saúde (LILACS), Sistema Online de Busca e Análise de Literatura Médica (MEDLINE) via Biblioteca Virtual em 
Saúde (BVS) e Scientific Electronic Library Online (SCIELO). Estudos incluídos indicaram haver relação entre os termos transtornos de aprendizagem e dificuldades de aprendizagem, sendo frequentemente citados: discalculia do desenvolvimento, transtorno do déficit de atenção e hiperatividade, dislexia do desenvolvimento e dificuldades de habilidades para leitura, escrita e matemática. Tais quadros foram qualificados pela verificação de déficits cognitivos de: alterações no processamento fonológico, memória de trabalho, atenção sustentada, acesso ao léxico mental e à velocidade de processamento linguístico e de informações. Resultados mostraram que transtornos de aprendizagem se associam às várias dificuldades de aprendizagem, qualificados por prejuízo no desenvolvimento acadêmico e na participação escolar dessas crianças a partir dos déficits cognitivos avaliados. É desafio importante avaliar e manejar tais déficits, exigindo identificar abordagens mais sensíveis aos complexos quadros de dificuldades de aprendizagem entre as crianças brasileiras, visando minimizar prejuízos no desempenho escolar; indicando, assim, necessidade de mais pesquisas contínuas para área de educação, inclusão e estimulação de habilidades escolares em prol do desenvolvimento infantil.

Palavras-chave: Desenvolvimento Infantil; Déficits Cognitivos; Desempenho Escolar; Transtornos de Aprendizagem.

\begin{abstract}
Complex cognitive changes manifest themselves among children in the school stage, causing difficulties from reading, writing, playing and learning, compromising school performance, child development and participation in everyday insertions. This literature review aims to identify which cognitive functions are most impaired among Brazilian school-age children with learning disabilities. Identification of studies in the databases: Latin American and Caribbean Literature in Health Sciences (LILACS), Online System of Search and Analysis of Medical Literature (MEDLINE) via Virtual Health Library (VHL) and Scientific Electronic Library Online (SCIELO). Studies have indicated that there is a relationship between the terms learning disorders and learning disabilities, often cited as developmental dyscalculia, attention deficit hyperactivity disorder, developmental dyslexia, and reading, writing and mathematical difficulties. Such pictures were qualified by the verification of cognitive deficits of: alterations in phonological processing, working memory, sustained attention, access to the mental lexicon and the speed of linguistic and information processing. Results showed that learning disorders are associated to the various learning difficulties, qualified by impairment in the academic development and in the school participation of these children from the evaluated cognitive deficits. It is an important challenge to evaluate and manage these deficits, requiring the identification of more sensitive approaches to the complex frameworks of learning difficulties among Brazilian children, in order to minimize impairments in school performance; thus indicating the need for more continuous research in the area of education, inclusion and stimulation of school skills in favor of child development.
\end{abstract}

Keywords: Learning; Child Development; Cognitive Impairments; School Performance; Learning Disorders.

\title{
Resumen
}

Los cambios cognitivos complejos se manifiestan entre los escolares, causando dificultades para leer, escribir, jugar y aprender, comprometiendo el rendimiento escolar, el desarrollo infantil y la participación en inserciones cotidianas. Esta revisión de la literatura tiene como objetivo identificar qué funciones cognitivas están más afectadas entre los niños brasileños en edad escolar con discapacidades de aprendizaje. Se identificaron estudios en las bases de datos: Literatura en Ciencias de la Salud de América Latina y el Caribe (LILACS), Sistema de búsqueda $y$ análisis de literatura médica en línea (MEDLINE) a través de la Biblioteca Virtual en Salud (BVS) y la Biblioteca Electrónica Científica En línea (SCIELO). Los estudios incluidos indicaron una relación entre los términos discapacidades de aprendizaje y discapacidades de aprendizaje, y a menudo se citaron: discalculia del desarrollo, trastorno por déficit de atención con hiperactividad, dislexia del desarrollo y dificultades con las habilidades de lectura, escritura y matemáticas. Tales condiciones fueron calificadas por la verificación de déficits cognitivos de: 
alteraciones en el procesamiento fonológico, memoria de trabajo, atención sostenida, acceso al léxico mental y la velocidad del procesamiento lingüístico y de la información. Los resultados mostraron que los trastornos de aprendizaje están asociados con diversas discapacidades de aprendizaje, calificadas por un desarrollo académico deficiente y la participación escolar de estos niños de los déficits cognitivos evaluados. Es un desafio importante evaluar y manejar tales déficits, ya que requiere la identificación de enfoques más sensibles a las discapacidades complejas de aprendizaje entre los niños brasileños, a fin de minimizar las deficiencias en el rendimiento escolar; indicando asi la necesidad de más investigación en curso en el área de educación, inclusión y estimulación de las habilidades escolares para el desarrollo infantil.

Palabras clave: Aprendizaje; Desarrollo infantil; Deficiencias cognitivas; Rendimiento escolar; Trastornos del aprendizaje.

\section{Introdução}

Desenvolvimento e aprendizagem são perceptíveis em diversos contextos da vida, em especial na escola. Segundo Piaget (1972) o desenvolvimento do conhecimento é uma embriogênese, que se dá através do processo global da evolução do corpo, de seu sistema nervoso e das funções mentais, estando a todo tempo atrelado do contexto biológico ao psicológico, envolvendo aí as estruturas para a formação do conhecimento. Este autor considera que a aprendizagem faz parte do desenvolvimento, sendo ele a base, pois o desenvolvimento é o processo espontâneo essencial e a aprendizagem funciona como uma função resultante desse processo total. Posto isto, pode-se expor o que ocorre em nível de desenvolvimento do conhecimento e da aprendizagem na idade escolar.

$\mathrm{Na}$ idade escolar, propriamente dita, concebida nos primeiros anos da infância, o desenvolvimento do conhecimento passará por uma fase chamada operatória concreta quando se iniciam as operações de classificação, ordenamento e construção de ideias comuns sobre noções de número, espaciais, temporais e demais de lógica elementar (Piaget, 1972). Rodrigues e Melchiori (2014) explicam que o período operatório concreto é a fase na qual ocorrem significativos avanços, pois as crianças começam a raciocinar a respeito de tudo ao seu redor de forma mais lógica e madura, porém suas habilidades são executadas apenas na concretude material, necessitando de visualização e experimentação por vias sensíveis corporais.

A forma de aprender é sempre característica individual de cada criança, o desenvolvimento infantil é marcado e influenciado por diversos fatores relacionados ao cotidiano e vivências pessoais daquela criança, em específico, num contexto de relações próprias com seu mundo em aprendizagem (Hemsing \& Skrsypsack, 2016). Esta noção 
de individualidade no desenvolvimento e na aprendizagem também será observada entre as crianças ditas com dificuldade de aprendizagem, somando-se suas inúmeras características biológicas, psicológicas e sociais, que dimensionam a complexidade de cada caso (Domingos, 2009). Destaca-se ainda que um quadro de dificuldades de aprendizagem não se apresenta de modo clássico, típico e/ou isolado numa criança, geralmente se manifesta estando associado a múltiplas possibilidades de investigação de fatores associados, que efetivamente contribuirão para detectar alterações no desenvolvimento infantil, valorizando aspectos relevantes ao prejuízo no desempenho acadêmico.

Definir aprendizagem é considerar fatores complexos que fazem parte da experiência escolar, verificáveis no desempenho acadêmico, a partir do desenvolvimento de múltiplos fatores associados entre si, bastante associado ao desenvolvimento infantil. Aprendizagem pode ser considerada como processo resultante de assimilação de habilidades ou modificações internalizadas à estrutura intelectual, relativas a mudanças comportamentais processualmente oportunizadas (Algeri, 2014), permanecendo em constante progressão e se construindo com estímulos específicos (Santos, 2009). Tendo em vista essa apresentação geral do termo, não só o ambiente e os estímulos fazem parte da construção da aprendizagem, mas de igual modo as habilidades ou características intrínsecas do indivíduo cooperarão para atingir níveis de aprendizagem relevantes ao desempenho acadêmico e participação de crianças na experiência escolar.

Diversos fatores podem influenciar no desempenho escolar das crianças, estes fortemente ligados ao próprio funcionamento da escola (Cavalcante \& Santos, 2013). Sendo assim, entende-se desempenho escolar como o resultado da interação da criança com a escola, seu entorno e problemáticas advindas com a experiência de educação formal escolar. Tal experiência se dá perante a caracterização de um ambiente constituído por diversos elementos que se interferem incessantemente na participação e no desenvolvimento de cada criança.

Ciasca (2005) considera que quando há alguma circunstância que atrapalhe o ato do aprender, isso exige que a criança use outra estratégia, seja interna ou externa, dimensionando uma oportunidade de adaptação e resposta ao seu desempenho acadêmico. Dentre as díspares questões que podem estar atreladas a essas dificuldades estão as de natureza cognitiva, foco de interesse no presente trabalho ao buscar detectar 
os principais déficits cognitivos, que crianças brasileiras possam apresentar quando consideradas dentro dos ditos transtornos de aprendizagem.

Para aprender, admite-se que os estudantes necessitem de estabelecer processos cognitivos essenciais, ou seja, formações de suas habilidades perceptuais e desenvolvimento de funções executivas complexas que os permitam entender, organizar, armazenar, comparar, seriar, resolver, evocar, integrar, dentre outras inúmeras capacidades, através das informações dadas e conhecimentos adquiridos ao longo de um processo contínuo de sua formação. Quando a criança apresenta dificuldades para utilizar, desenvolver, requisitar, tais habilidades básicas e capacidades desenvolvidas, é relevante destacar que as suas funções cognitivas não permitirão solucionar os grandes problemas para a assimilação das informações que lhe serão passadas (Almeida, 2002; Santos, 2009), indicando uma experiência escolar caracterizada por mau funcionamento no desempenho escolar, qualificado por inúmeras dificuldades da aprendizagem. Com essa afirmativa, pode-se entender que a aprendizagem e as estruturas cognitivas estão intimamente ligadas, produzindo grande parte do desenvolvimento de habilidades na criança em idade escolar, sendo integralmente requisitadas para estimar possibilidades de desenvolvimento infantil e verificar eficiência da aprendizagem no desenvolvimento escolar pela experiência formal da vida acadêmica.

Quando se fala sobre problemas de aprendizagem na literatura a tarefa torna-se bastante desafiadora, visto que não há uma concordância geral entre os autores. Não havendo, portanto, definitivo consenso conceitual sobre o que são os transtornos de aprendizagem, existem diversos termos e definições usados para tentar caracterizar tais problemas de aprendizagem em geral (Figueiredo, Quevedo, Gomes, \& Pappen, 2007; Germano \& Capellini, 2011; Oliveira, Germano, \& Capellini, 2015). Defini-los envolve identificar que dificuldades de aprendizagem explicam sua apresentação complexa, variável de caso a caso entre as crianças durante sua experiência escolar formativa.

Especificamente, as dificuldades de aprendizagem ocorrem no período de escolarização e podem ser definidas como complicações na assimilação de algo que é ensinado, tais complicações são tidas como os déficits que o aluno encontra para captar conteúdos em sala de aula Oliveira, Germano, \& Capellini, 2015). De forma geral, os autores apontam que as principais características das dificuldades de aprendizagem compõem um grupo de déficits cognitivos, que resultam em baixo desempenho do aluno em tarefas acadêmicas, principalmente de leitura, escrita e cálculo. 
As dificuldades de aprendizagem podem decorrer de diversos fatores distintos (Antunes, Freire \& Crenite, 2013; Granzotti, Furlan, Domenis, \& Fukuda, 2013): relacionados a problemas no método de ensino, pouca ou nenhuma adaptação do aluno àquele sistema escolar, além dos aspectos psicossociais relacionados, como baixa renda financeira, questões emocionais e problemas sócio familiares e os aspectos preponderantemente cognitivos, como funcionamento deficitário de determinadas funções neuropsicológicas, lesões, privação de estímulos e outros quadros passíveis de diagnóstico etiológico. Sendo assim, as ditas dificuldades de aprendizagem são sempre um termo mais genérico, que pode abarcar ou ter alguma relação com os outros termos citados acima e relacionam-se fortemente ao contexto escolar do aluno, comumente detectáveis entre os transtornos da aprendizagem de indivíduos em idade escolar.

O transtorno de aprendizagem, por sua vez, é um termo que pode ser definido como alteração sistemática de um conjunto de dificuldades específicas - que possui relação com disfunções cognitivas complexas e quadros neurológicos específicos, acarretando um quadro de fracasso contínuo, principalmente, em atividades escolares e nos demais contextos para a vida de relação, os quais a criança em idade escolar se insere e irá se desenvolver, respondendo insatisfatoriamente quando solicitadas funções relacionadas à capacidade de aprender. Esta caracterização não deve ser confundida com dificuldades ou déficits de aprendizagem, pois estes tratam de um conceito mais abrangente e relacionam-se com outros tipos de fatores gerais como a experiência acadêmica no ambiente escolar, as relações sociais ou até mesmo a forma de ensino do professor, envolvendo até a didática e o sistema educacional vigente (Silva \& Capellini, 2013).

Dentro do construto dos transtornos específicos de aprendizagem (TEA), existem classificações que vão ter relação estrita com o tipo de habilidade afetada naquela criança, cada subtipo comprometerá alguma área de aprendizagem - compreendida aqui como função cognitiva de natureza integrativa já maturada, podendo essas classificações assumir apresentações de prejuízo em atividades específicas e/ou habilidades de leitura, de expressão da escrita, das operações e dos processamentos matemáticos, das funções de linguagem, dos aspectos comportamentais, dentre outras funções cognitivas que poderão estar muito comprometidas, inclusive admitindo-se que nenhum transtorno terá consequências idênticas ao outro (American Psychiatry Association, 2014; Oliveira, 
Germano, \& Capellini, 2015), isso influenciará na escola e os outros meios onde a criança está inserida.

Após essa compreensão sobre os transtornos de aprendizagem, interesse primordial neste presente estudo, é importante reforçar que sua manifestação ocorre desde o início do desenvolvimento de crianças em idade escolar, não sendo decorrente simplesmente de uma falta da oportunidade de aprender, traumatismo ou de doença cerebral adquirida, assumindo disfunções das capacidades de aprendizagem ao longo de todo o desenvolvimento para além da vida acadêmica. Desse modo o objetivo do estudo é revisar a literatura para identificar quais estudos reportaram funções cognitivas prejudicadas entre as crianças brasileiras, em idade escolar, que apresentem transtornos de aprendizagem, considerando nos estudos nacionais quaisquer dificuldades de aprendizagem ou déficits cognitivos, independentemente da nomenclatura adotada. Inclui-se nesta verificação revisional o objetivo secundário de qualificar quais funções cognitivas estão mais associadas a determinados transtornos e/ou a dificuldades de aprendizagem e, por último, também sistematizar quais profissionais desenvolveram tais estudos na área da educação e/ou desenvolvimento infantil sobre crianças brasileiras, em idade escolar, com transtornos de aprendizagem, buscando mapear, finalmente, a publicação nacional na última década.

\section{Método}

A revisão de literatura foi realizada através de buscas avançadas em 03 bases de dados: 1) Literatura Latino-Americana e do Caribe em Ciências da Saúde (LILACS), 2) Sistema Online de Busca e Análise de Literatura Médica (MEDLINE) via Biblioteca Virtual em Saúde (BVS) e 3) Scientific Electronic Library Online (SCIELO). A pesquisa por publicações de estudos primários ocorreu pela utilização dos descritores: "aprendizagem", "criança" e "cognição". Para ampliar os resultados foram também utilizados os termos "desempenho" e "transtorno de aprendizagem", combinando-os pelas ferramentas de buscas avançadas das bases consultadas. Desta forma as diferentes combinações podem ser demonstradas: "transtorno de aprendizagem, criança e desempenho"; "criança e cognição"; "transtorno de aprendizagem e criança"; "transtorno de aprendizagem, criança e cognição”. 
A busca dos artigos foi realizada, utilizando os filtros de artigos escritos do ano de 2007 a 2017, priorizando a publicação mais recente da última década. Os critérios de inclusão dos estudos foram: a) estudos brasileiros; b) nos idiomas Português, Espanhol e Inglês; c) envolvendo crianças ditas em idade escolar, na faixa entre 07 a 12 anos, com dificuldades de aprendizagem e que reportassem avaliação de aspectos cognitivos das mesmas; d) que fossem estudos de pesquisas primárias do tipo observacionais, experimentais e relatos de caso. Para a exclusão admitiu-se os critérios de: a) estudos publicados antes de 2007; b) publicações de estudos exclusivamente de crianças com menos de 07 anos e/ou apenas adolescentes; c) publicações de revisões, editoriais, trabalhos de congressos e resenhas.

Apesar de alguns artigos envolverem crianças em idade escolar com idades abaixo ou acima dos critérios de seleção, tais estudos foram utilizados, pois foi levado em consideração apenas os dados avaliativos das crianças, extraídos em conformidade com a referida faixa etária pretendida, chamada de escolar, a ser destacado na discussão.

Os estudos foram identificados a partir do título e leitura dos resumos. Para a seleção, procedeu-se com a leitura na íntegra das publicações. Na fase final de inclusão, atribuiu-se os critérios já mencionados de inclusão e exclusão. Não houve critérios com relação à base teórica adotada pelos estudos incluídos.

Optou-se também por consulta à plataforma LATTES do Conselho Nacional de Desenvolvimento Científico e Tecnológico (CNPq) para busca e verificação das formações profissionais dos autores dos estudos incluídos nesta revisão, visando contribuir para discussão sobre o perfil das publicações nacionais sobre o tema, conforme será demonstrado a seguir.

\section{Resultados}

Foram incluídos 23 estudos nesta revisão bibliográfica sobre a publicação nacional de crianças com dificuldades de aprendizagem em idade escolar. Os resultados apresentados no quadro abaixo referem-se a identificação dos estudos incluídos nesta revisão bibliográfica, com demonstrativo das dificuldades de aprendizagem verificadas e os respectivos déficits cognitivos relacionados nas publicações respectivas, entre as crianças em idade escolar (Quadro 1). Observa-se que do total dos estudos incluídos, um estudo foi repetido no quadro esquemático (Miranda et al., 2012), pois os dados serviram 
para análise diferenciada em mais de um transtorno de aprendizagem, havendo a metodologia criteriosa de análise estratificada nestes casos.

Os estudos foram sistematizados em ordem crescente de tempo de publicação e organizados em categorias das dificuldades de aprendizagem verificadas, indo das dificuldades de leitura, escrita e matemática, que foram mais frequentes, podendo ser acompanhadas por comorbidades ou quadros de transtornos de aprendizagem, até as alterações menos frequentes, de dificuldades ou transtornos de aprendizagem.

Reporta-se que 11 (47,82\%) estudos tratam das dificuldades relacionadas à leitura e escrita e à matemática, $07(30,43 \%)$ referem-se à crianças com dislexia do desenvolvimento (DL), 06 (26,09\%) refere-se às crianças com transtorno de déficit de atenção e hiperatividade (TDAH) e, como última categoria, apenas um estudo $(4,35 \%)$ aborda crianças em idade escolar com discalculia do desenvolvimento combinada com dislexia (DDc). Alguns artigos dessa última classificação investigam alteração em apenas uma habilidade, verificando alterações para leitura somente ou matemática, dificultando sua aglutinação em categorias de dificuldades de aprendizagem mais amplamente.

Quadro 1 - Transtornos ou dificuldades de aprendizagem identificados e déficits cognitivos relacionados.

\begin{tabular}{|c|c|c|}
\hline $\begin{array}{l}\text { Estudos } \\
\text { (autores e ano } \\
\text { de publicação) }\end{array}$ & $\begin{array}{l}\text { Dificuldade de } \\
\text { Aprendizagem }\end{array}$ & $\begin{array}{l}\text { Déficits cognitivos relacionados aos } \\
\text { transtornos de aprendizagem }\end{array}$ \\
\hline $\begin{array}{l}\text { Figueiredo et } \\
\text { al. (2007) }\end{array}$ & & $\begin{array}{l}\text { Prejuízos na organização perceptual; } \\
\text { alterações na atenção e concentração; } \\
\text { prejuízos na organização visual; } \\
\text { prejuízos no pensamento abstrato. }\end{array}$ \\
\hline $\begin{array}{l}\text { Nicolielo, } \\
\text { Gejão, Lopes- } \\
\text { Herrea, \& } \\
\text { Maximino } \\
(2014)\end{array}$ & & $\begin{array}{l}\text { Alteração nas habilidades de } \\
\text { consciência fonológica; } \\
\text { alteração na memória de curto prazo. }\end{array}$ \\
\hline $\begin{array}{l}\text { Salles \& } \\
\text { Parente (2008) }\end{array}$ & & $\begin{array}{l}\text { Alteração na consciência fonológica; } \\
\text { alteração na memória verbal; } \\
\text { alteração na linguagem oral; } \\
\text { alteração na velocidade de } \\
\text { processamento. }\end{array}$ \\
\hline $\begin{array}{l}\text { Kawano, Kida, } \\
\text { Carvalho, \& } \\
\text { Ávila (2011) }\end{array}$ & & $\begin{array}{l}\text { Alterações no processamento } \\
\text { fonológico (processamento da } \\
\text { informação fonológica, decodificação e } \\
\text { reconhecimento de palavra, mecanismo } \\
\text { conversor grafema-fonema); } \\
\text { alteração na fluência de leitura }\end{array}$ \\
\hline
\end{tabular}




\begin{tabular}{|c|c|c|}
\hline $\begin{array}{l}\text { Silva \& } \\
\text { Capellini } \\
(2011 a)\end{array}$ & \multirow[t]{7}{*}{$\begin{array}{l}\text { Dificuldades } \\
\text { relacionadas à leitura, à } \\
\text { escrita e à matemática }\end{array}$} & $\begin{array}{l}\text { Alteração na consciência fonológica; } \\
\text { alteração no processamento auditivo; } \\
\text { prejuízos na memória direta e indireta } \\
\text { para dígitos; déficit na velocidade de } \\
\text { nomeação. }\end{array}$ \\
\hline $\begin{array}{l}\text { Silva \& } \\
\text { Capellini } \\
(2011 b)\end{array}$ & & $\begin{array}{l}\text { Alteração na consciência fonológica, } \\
\text { sintática e semântica; } \\
\text { alteração na memória de trabalho; } \\
\text { falhas no acesso ao léxico mental; } \\
\text { alteração no mecanismo gerativo } \\
\text { grafema-fonema. }\end{array}$ \\
\hline $\begin{array}{l}\text { Ferreira et al. } \\
(2012)\end{array}$ & & $\begin{array}{l}\text { Prejuízos no processamento não } \\
\text { simbólico. }\end{array}$ \\
\hline $\begin{array}{l}\text { Corso, Sperb \& } \\
\text { Salles (2013) }\end{array}$ & & $\begin{array}{l}\text { Alteração na memória de trabalho } \\
\text { visuoespacial; } \\
\text { prejuízos na fluência verbal ortográfica } \\
\text { e semântica; } \\
\text { alterações na linguagem escrita de } \\
\text { palavras e pseudopalavras (sons, } \\
\text { 109nomatopeias, expressões oralizadas } \\
\text { em contextos próprios da leitura ou } \\
\text { escrita, bem como neologismos e } \\
\text { representações livres artísticas do } \\
\text { texto). }\end{array}$ \\
\hline $\begin{array}{l}\text { Granzotti et al. } \\
\text { (2013) }\end{array}$ & & $\begin{array}{l}\text { Prejuízos na consciência fonológica } \\
\text { suprafonêmica e fonêmica; } \\
\text { alteração na memória de trabalho; } \\
\text { prejuízos memória de trabalho } \\
\text { fonológica. }\end{array}$ \\
\hline $\begin{array}{l}\text { Soares, } \\
\text { Sanches, Alves, } \\
\text { Carvallo, \& } \\
\text { Cárnio (2013) }\end{array}$ & & $\begin{array}{l}\text { Alterações no processamento temporal } \\
\text { e auditivo; } \\
\text { alteração na consciência fonológica. }\end{array}$ \\
\hline $\begin{array}{l}\text { Oliveira, } \\
\text { Germano \& } \\
\text { Capellini } \\
(2015)\end{array}$ & & $\begin{array}{l}\text { Alteração na consciência fonológica; } \\
\text { alteração percepção fonêmica; } \\
\text { falhas na ordenação temporal de } \\
\text { julgamento; falhas na identificação e } \\
\text { discriminação fonêmica e silábica. }\end{array}$ \\
\hline $\begin{array}{l}\text { Martins \& } \\
\text { Triginelli } \\
\text { (2009) }\end{array}$ & & Alteração da consciência fonológica. \\
\hline $\begin{array}{l}\text { Germano \& } \\
\text { Capellini } \\
(2011)\end{array}$ & & $\begin{array}{l}\text { Déficit fonológico (comprometimento } \\
\text { na formação de representações internas } \\
\text { da estrutura fonológica da palavra); } \\
\text { sobrecarga da memória fonológica } \\
\text { (causada pelo déficit fonológico); } \\
\text { prejuízos nas habilidades silábicas com } \\
\text { alterações para as habilidades e } \\
\text { funções de contagem, identificação, }\end{array}$ \\
\hline
\end{tabular}




\begin{tabular}{|c|c|c|}
\hline & \multirow[t]{6}{*}{$\begin{array}{l}\text { Dislexia do } \\
\text { desenvolvimento (DL) }\end{array}$} & $\begin{array}{l}\text { síntese e análise, deleção, combinação } \\
\text { de informações. }\end{array}$ \\
\hline $\begin{array}{l}\text { Lima, Azoni, \& } \\
\text { Ciasca (2011) }\end{array}$ & & $\begin{array}{l}\text { Alterações na atenção; } \\
\text { baixo desempenho das funções } \\
\text { executivas; } \\
\text { déficits no componente fonológico da } \\
\text { linguagem. }\end{array}$ \\
\hline $\begin{array}{l}\text { Miranda et al. } \\
\text { (2012) }\end{array}$ & & $\begin{array}{l}\text { Alteração no controle inibitório; } \\
\text { impulsividade; } \\
\text { alteração na atenção sustentada. }\end{array}$ \\
\hline $\begin{array}{l}\text { Germano, } \\
\text { Pinheiro \& } \\
\text { Capellini } \\
(2013)\end{array}$ & & $\begin{array}{l}\text { Alteração do processamento léxico; } \\
\text { alteração na consciência fonológica; } \\
\text { alteração na memória verbal. }\end{array}$ \\
\hline $\begin{array}{l}\text { Kida, Ávilla \& } \\
\text { Capellini } \\
\text { (2015) }\end{array}$ & & $\begin{array}{l}\text { Alteração no processamento léxico; } \\
\text { alteração no processamento sintático; } \\
\text { falhas na representação fonológica. }\end{array}$ \\
\hline $\begin{array}{l}\text { Silva, Ribeiro, } \\
\text { \& Santos } \\
(2015)\end{array}$ & & $\begin{array}{l}\text { Prejuízos na decodificação simbólica } \\
\text { numérica. }\end{array}$ \\
\hline $\begin{array}{l}\text { Messina \& } \\
\text { Tiedemann } \\
(2009)\end{array}$ & \multirow{5}{*}{$\begin{array}{l}\text { Transtorno do déficit de } \\
\text { atenção e hiperatividade } \\
\text { (TDAH) }\end{array}$} & $\begin{array}{l}\text { Alteração na atenção; } \\
\text { alteração na memória de trabalho; } \\
\text { lentificação na velocidade de } \\
\text { processamento; falha na tomada de } \\
\text { decisão; } \\
\text { dificuldade no planejamento; } \\
\text { falhas na abstração. }\end{array}$ \\
\hline $\begin{array}{l}\text { Okuda et al. } \\
(2011)\end{array}$ & & $\begin{array}{l}\text { Alteração das funções executivas } \\
\text { (planejamento, organização e execução } \\
\text { do ato motor). }\end{array}$ \\
\hline $\begin{array}{l}\text { Silva, Cunha \& } \\
\text { Capellini } \\
\text { (2011) }\end{array}$ & & $\begin{array}{l}\text { Alteração na atenção; } \\
\text { alterações na autorregulação; } \\
\text { alteração na memória de trabalho; } \\
\text { alteração na consciência fonológica. }\end{array}$ \\
\hline $\begin{array}{l}\text { Miranda et al. } \\
(2012)\end{array}$ & & $\begin{array}{l}\text { Alteração na atenção (erro de } \\
\text { omissão); } \\
\text { falha no controle inibitório (erro de } \\
\text { comissão); inconsistência na taxa de } \\
\text { resposta (erro padrão do tempo de } \\
\text { reação); } \\
\text { maior nível de impulsividade } \\
\text { (perseverações); } \\
\text { pouca vigilância (alteração no intervalo } \\
\text { entre estímulos). }\end{array}$ \\
\hline $\begin{array}{l}\text { Oliveira et al. } \\
(2013)\end{array}$ & & $\begin{array}{l}\text { Alterações nos processos léxico, } \\
\text { semântico e fonológico; } \\
\text { falhas na codificação e decodificação } \\
\text { simbólica; alteração na atenção; } \\
\text { percepção prejudicada; }\end{array}$ \\
\hline
\end{tabular}




\begin{tabular}{|l|l|l|}
\hline \multirow{2}{*}{$\begin{array}{l}\text { Alves et al. } \\
(2014)\end{array}$} & alteração na memória seletiva. \\
\cline { 3 - 3 } & $\begin{array}{l}\text { Alteração na consciência fonológica; } \\
\text { falhas no acesso ao léxico mental } \\
\text { (nomeação automática rápida } \\
\text { principalmente em alunos com } \\
\text { comorbidades e mais novos). }\end{array}$ \\
\hline $\begin{array}{l}\text { Silva, Ribeiro, } \\
\text { \& Santos } \\
(2015)\end{array}$ & $\begin{array}{l}\text { Discalculia do } \\
\text { desenvolvimento } \\
\text { combinada com dislexia } \\
\text { (DDc) }\end{array}$ & $\begin{array}{l}\text { Prejuízos na decodificação simbólica } \\
\text { numérica; } \\
\text { prejuízos na transcodificação numérica } \\
\text { e processamento numérico. }\end{array}$ \\
\hline
\end{tabular}

Legenda: DL $=$ Dislexia do desenvolvimento; TDAH $=$ Transtorno de déficit de atenção e hiperatividade; DDc $=$ Discalculia do desenvolvimento combinada com dislexia.

Quanto à verificação da formação dos autores nas publicações incluídas nesta revisão, de acordo com a metodologia informada de consulta à Plataforma Lattes, os profissionais que mais expressivamente publicaram na última década foram fonoaudiólogos e psicólogos, outros profissionais, com formações diferentes, também compuseram as publicações, além de um grupo de pesquisadores multiprofissionais. Portanto, no tocante ao perfil dos autores que publicaram nacionalmente sobre crianças em idades escolares na temática de alterações cognitivas pelos quadros de dificuldade e/ou transtornos de aprendizagem, pode-se qualificar da seguinte forma. Em maior número $(52,1 \%)$ as publicações foram realizadas pelo grupo de somente fonoaudiólogos, a destacar: Nicolielo et al. (2014), Salles e Parente (2008), Germano e Capellini (2011), Kawano et al. (2011), Silva e Capellini (2011a), Silva e Capellini (2011b), Silva, Cunha e Capellini (2011), Germano, Pinheiro e Capellini, (2013), Granzotti et al. (2013), Soares, Sanches, Alves, Carvallo, \& Cárnio (2013), Kida, Ávilla e Capellini (2015) e Oliveira, Germano e Capellini (2015). O grupo intermediário nas publicações foi composto pelas pesquisas de somente psicólogos, totalizando $13 \%$ do universo de estudos incluídos nesta revisão, a saber: Figueiredo et al. (2007), Martins e Triginelli (2009) e Silva, Ribeiro e Santos (2015). Por último, totalizando 34,7\% tem-se o grupo de pesquisas realizadas multiprofissionalmente, aonde se alocam os estudos de: Messina e Tiedemann (2009), Lima, Azoni e Ciasca (2011), Okuda et al. (2011), Ferreira et al. (2012), Miranda et al. (2012), Corso, Sperb e Salles (2013), Oliveira et al. (2013) e Alves et al. (2014).

Dos 23 artigos incluídos, pode-se elencar como principais déficits cognitivos verificados nos quadros de dificuldade ou transtorno de aprendizagem, entre as crianças brasileiras em idade escolar: alterações de linguagem, alterações de memória, alterações de velocidade de processamento (Fig. 01). Em valores intermediários, verificou-se como 
alteradas as funções de atenção, funções executivas e da percepção. Apenas um estudo reportou avaliação das alterações no tocante à avaliação das habilidades visuais entre as crianças-alvo desta revisão.

\section{Figura 01 - Representação de déficits cognitivos avaliados nos estudos incluídos.}

Principais déficits cognitivos encontrados em crianças em idade escolar com transtorno ou dificuldades de aprendizagem

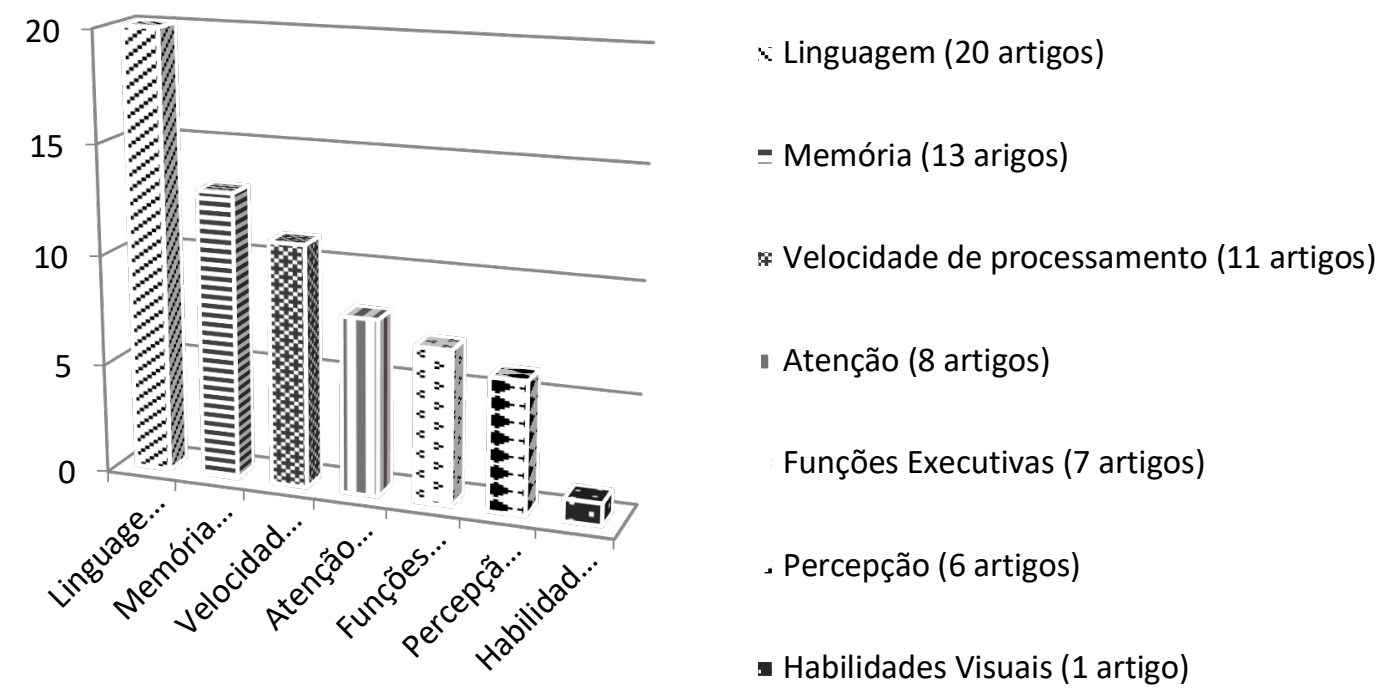

Fig.1 - Gráfico indicativo do número de artigos onde as habilidades cognitivas foram verificadas como afetadas entre as crianças brasileiras em idade escolar com dificuldades ou transtorno de aprendizagem, conforme análise dos estudos incluídos nesta revisão da publicação nacional da última década.

Fonte do gráfico: própria autoria.

Legenda: $\mathrm{L}=$ linguagem; $\mathrm{M}=$ memória; $\mathrm{V}=$ velocidade de processamento; $\mathrm{A}=$ atenção/ $\mathrm{F}=$ funções executivas; $\mathrm{P}=$ percepção; $\mathrm{H}=$ habilidades visuais.

\section{Discussão}

Os estudos incluídos apresentaram consonância com o pensamento piagetiano, destacando ênfase na compreensão das funções cognitivas que sirvam ao contexto do desenvolvimento da aprendizagem por parte das crianças neles abordadas. Esta verificação de afinidade entre os estudos indica que a difusão de intervenções construtivistas com crianças em dificuldades de aprendizagem favorece um amplo entendimento de que - no tocante às crianças brasileiras, importa diretamente relacionar todos os aspectos que dificultam sua participação nos contextos da aprendizagem escolar. 
Os transtornos de aprendizagem se referem a um grupo de dificuldades mais específicas com a característica central de possuir alguma disfunção neurocognitiva, a qual favorecerá possíveis fracassos em determinadas habilidades relacionadas ao aprendizado acadêmico e ao desenvolvimento da capacidade integrativa de aprendizagem que possivelmente interferirá no envolvimento com ocupações. Tais transtornos são evidenciados nas atividades escolares, advindo com dificuldades em habilidades, podendo ser de escrita, leitura, cálculo ou relações dessas habilidades em outras tarefas da vivência em formação acadêmica e que dela derivem. Nesses transtornos, o funcionamento cerebral se apresentará atípico com alterações em algum nível na assimilação, processamento ou armazenamento da informação aprendida (Ciasca, 2005; Silva \& Capellini, 2013), evidenciando alterações neuro-cognitivo-funcionais bastante relevantes. Assim, podem-se observar tais características nas crianças abordadas nos estudos, pois elas apresentaram dificuldades relacionadas ao aprendizado acadêmico, sendo tais características decorrentes de disfunções em capacidades cognitivas, as quais foram expostas na sistematização dos resultados do presente trabalho.

Noutro aspecto, tem-se o termo abrangente denominado dificuldades de aprendizagem. Por exemplo, o termo dislexia - segundo a Associação Americana de Psiquiatria (APA) (Apa, 2014), é um conjunto de dificuldades de aprendizagem, no qual são evidenciados problemas no reconhecimento preciso ou fluente de palavras, na decodificação e reconhecimento ortográfico.

Muszkat e Mello (2009) afirmam que na dislexia, a criança possui uma compreensão de fala, porém a dificuldade reside na decomposição fonológica da mesma e a leitura também é prejudicada, tornando-se lentificada. Nesse caso, tem se que tais crianças também não apresentam facilidade de reconhecer palavras incomuns a sua realidade ou decifrar pseudopalavras, enfrentando também problemas para resolver soletração e rimas. Destaca-se que a principal diferença entre escolares com dislexia e leitores eficientes encontra-se na competência gramatical, na qual os escolares com dificuldade apresentam menor percentual de sentenças corretas no que se refere a essa habilidade (Kida, Ávilla, \& Capellini, 2015). Assim, citar a dislexia permite exprimir a complexidade envolvida no tocante às referidas dificuldades de aprendizagem não somente para a vida acadêmica, mas para aspectos amplos do desenvolvimento dos sujeitos acometidos. 
Como explica Miranda et al. (2005), na dislexia ocorre um déficit linguístico, mais precisamente uma falta de habilidade no nível fonológico, o que concorda com o pensamento de Argolo (2005) - a qual esclarece que a dificuldade para o reconhecimento da palavra de forma imediata é a principal dificuldade da criança disléxica. Tais afirmações destes autores demonstram que o principal déficit cognitivo encontrado em escolares disléxicos está intimamente relacionado ao componente fonológico da linguagem. O que dimensiona o alcance da dificuldade de aprendizagem para a formação para além da experiência escolar.

Acrescendo apresentações clínicas mais híbridas dos casos de transtorno de aprendizagem com as dificuldades de aprendizagem, teríamos casos ainda mais complexos a definir e acompanhar. Sobre as características essenciais do TDAH, a APA (2014) aponta a desatenção e/ou hiperatividade-impulsividade, as quais interferem no funcionamento ou no desenvolvimento da criança, onde os sintomas de desatenção manifestam-se de forma comportamental nas divagações em tarefas, falta de persistência, dificuldade de manter o foco e desorganização. As dificuldades vivenciadas extrapolam limites entre vivência acadêmica e formação pelo desenvolvimento, exigindo destas crianças formas de interagir e integrar-se ao grupo de certa forma desafiadora. Verificase que as crianças acometidas podem simplesmente não reconhecer a presença de limites ou não corresponder aos comandos e solicitações do meio facilmente ditas, como se operassem com falta de compreensão, já os sintomas de hiperatividade são atividade motora em excesso (como uma criança agitada ou incontrolável) quando não apropriado ao invés de produzir comportamentos mais eficazes às interações diversas.

Genes (2005) concorda com tais compreensões sobre a entidade clínica de TDAH e ressalta que o transtorno pode perfazer consequências comprometedoras para as funções sociais, acadêmicas ou profissionais do indivíduo que vão persistir por, no mínimo 06 meses, sendo observadas em dois ou mais locais frequentados pelo indivíduo. Estes seriam então os principais sintomas observados em crianças com TDAH. O que qualifica seu comprometimento mais extensivamente entre um quadro híbrido de transtorno de aprendizagem com dificuldades de aprendizagem.

Quanto ao processamento da aprendizagem é requerida a compreensão sobre funções específicas da linguagem, que envolvem processos atencionais, memória funcional e aspectos operacionais relativos às funções executivas para resolução de problemas na compreensão e comunicação. Destaca-se entre esta amplitude de funções 
cognitivas envolvidas na linguagem: a consciência fonológica (Guimarães, 2002; Nunes, Frota, \& Mousinho, 2002; Byrne \& Barnsley, 1989). A consciência fonológica tem estreita ligação com aprendizagem da leitura e escrita, já bem estabelecida conforme verificação dos estudos incluídos nesta revisão.

É possível indicar que a manipulação consciente fonêmica (dos sons) poderá favorecer a linguagem escrita, do mesmo modo que a aprendizagem da leitura alfabética contribuirá para a consciência fonêmica, pois existe um componente auditivo e visual no sistema alfabético que faz uma correspondência grafofonêmica (Guimarães, 2002; Nunes, Frota, \& Mousinho, 2002; Byrne e Barnsley, 1989) - facilitando coordenar estímulos e promover integração entre funções perceptuais (visuo-auditivas), práxicas pela escrita e linguísticas pela compreensão lógico-abstrata da letra em si. Desse modo, os estudos incluídos são favoráveis à compreensão de que as dificuldades de aprendizagem no caso do TDAH levam as crianças acometidas a apresentarem déficits em habilidades específicas do processamento fonológico, o que prejudica sua capacidade de leitura e escrita durante à vivência da idade escolar.

Em termos estatísticos, considerando o amplo grupo populacional das crianças diagnosticadas com esse transtorno (TDAH) nos contextos da vida escolar, dois terços também demonstram ter comorbidades associadas (Genes, 2005). Nas crianças que apresentam o transtorno somado a comorbidades, as características associadas podem ser variadas, podendo existir limiar baixo para frustrações, irritabilidade, mudanças bruscas de humor e geralmente, até mesmo quando há somente essas questões associadas sem o transtorno, o desempenho do escolar pode ficar bastante comprometido (American Psychiatry Association, 2014). Sugere-se então que essas crianças com dificuldades de aprendizagem participem de atividades que objetivem o desenvolvimento da consciência fonológica, favorecendo sua integração social a partir de facilitação do desenvolvimento e estímulo a aprendizagem em funções cognitivas específicas, como é o caso da linguagem pela consciência fonológica, portanto.

Ao abordar especificamente a leitura e explicar como funciona o cérebro quando se lê, Gabriel (2008) explica que o ato de ler é produzir um significado a partir do estabelecimento de uma relação entre o grafema (símbolo) e o fonema (som). O mecanismo gerativo para estabelecer essa relação grafema-fonema mostrou-se defasada em alguns estudos que envolveram crianças com dificuldades nessa habilidade específica e os artigos incluídos apontaram que crianças com dificuldades na habilidade de leitura 
podem apresentar desrespeito a essa correspondência grafema-fonema por dificuldades na leitura feita pela rota fonológica, pois essa via permite a leitura por conversão grafema fonema (Kawano et al., 2011; Silva \& Capellini, 2011b). Desta forma, destaca-se um mecanismo disfuncional que compromete o processamento linguístico satisfatório à exigência de aprendizagem nos contextos da vivência acadêmica, culminando na percepção da frustração e relatos de insucesso.

Retomando as alterações na habilidade de leitura e englobando-a com a alteração na habilidade de escrita, os estudos apontaram relação de tais déficits nessas habilidades à lentidão na velocidade de processamento, falhas no acesso ao léxico mental e forte associação com alteração na memória de trabalho. Tais alterações cognitivo-funcionais interferem nas habilidades globais requeridas para a formação acadêmica, pois crianças com dificuldades na aprendizagem podem apresentar insucesso em tarefas que necessitem de velocidade e precisão no reconhecimento de palavras, o que é muito comum na condução de conteúdos curriculares em escolas típicas (Miranda et al., 2005; Silva \& Capellini, 2011a).

Respostas integradoras para as atividades acadêmicas exigem a operação entre as capacidades de resposta, tempo, coordenação de estímulos. Cada comportamento a ser produzido exige integridade de habilidades de acesso ao léxico mental que seria desde rápida identificação da palavra com significado, palavras essas que já precisariam estar previamente armazenadas na memória (Miranda et al., 2005; Silva \& Capellini, 2011a), à interação de conhecimentos prévios a ajustes de novas respostas mais favoráveis a situações imprevistas, passíveis de envolvimento com resolução de problemas. Visto isto, entende-se que crianças que apresentam dificuldades em habilidades específicas de leitura e escrita, podem encontrar grandes barreiras para executá-las, sabendo que para tarefas de leitura e escrita tais habilidades são recrutadas de forma interligada e precisam estar íntegras.

Na discussão sobre aplicação da aprendizagem, é possível identificar campos de investigação mais favoráveis à verificação das dificuldades que incidem da vivência acadêmica e podem interferir extensivamente nas demais capacidades das crianças acometidas. Como é o caso da Matemática. Considera-se como dificuldades relacionadas à Matemática, aquelas denominadas de discalculia do desenvolvimento (Silva, Ribeiro, \& Santos, 2015). A APA (2014) define a discalculia como "um padrão de dificuldades caracterizado por problemas no processamento de informações numéricas, aprendizagem 
de fatos aritméticos e realização de cálculos precisos ou fluentes" (p. 67). Este termo “discalculia do desenvolvimento" foi introduzido por Ladislav Kosc em 1974 (citado por Silva, Ribeiro, \& Santos, 2015), o qual classificou a discalculia em subtipos, servindo de base para outros pesquisadores em suas pesquisas sobre o assunto.

No estudo em que se investigou o desempenho de crianças com discalculia do desenvolvimento (Silva, Ribeiro, \& Santos, 2015), foi conclusivo que elas apresentaram mais dificuldade em sistemas específicos da cognição numérica, as quais se mostraram em desvantagem quando comparadas a crianças do grupo controle nos sistemas: compreensão numérica, transcodificação numérica, produção numérica e cálculo, sendo os dois últimos os mais significativos. Ou seja, é a verificação da discalculia do desenvolvimento que permite localizar um importante quantitativo de pessoas acometidas por dificuldades de aprendizagem, cujo prejuízo ao funcionamento acadêmico e à preparação para habilidades sociais se torna um desafio pior à experiência escolar. Identificando-se prejuízo extensivo à aprendizagem e ao desempenho acadêmico satisfatório.

Em linhas gerais, crianças em idade escolar com transtornos/dificuldades de aprendizagem apresentam um perfil cognitivo abaixo do esperado em diversas habilidades cognitivas, destacando-se forte ligação com processamento da linguagem e atenção (de acordo com as avaliações em testes padronizados realizadas), sendo estas parte de um construto indispensável para o aprendizado acadêmico (Alves et al., 2014) os comprometimentos vão ainda além prejudicando no funcionamento pessoal, social, acadêmico ou profissional, não se restringindo ao contexto escolar (Figueiredo et al., 2007; Nicolielo et al., 2014; Miranda et al., 2012). Importante salientar que os déficits cognitivos podem apresentar padrões distintos em crianças com as mesmas dificuldades, indicando que tais comprometimentos são múltiplos e necessitam de intervenções específicas que deem suporte compatível àquelas crianças (Salles \& Parente, 2008).Essas informações apontam para a grande importância de uma avaliação sensível e precisa aos diferentes perfis de desempenho escolar apresentados por cada criança.

\section{Considerações finais}

Ao revisar as pesquisas incluídas verificou-se que há certa confusão no uso de termos entre transtornos e dificuldades de aprendizagem, pois além de não haver uma 
concordância conceitual geral na literatura consultada, alguns estudos ainda nomearam essas complexidades de formas diferentes, muitas vezes querendo abordar os mesmos aspectos classificatórios.

A ênfase na publicação de pesquisadores nacionais sobre as dificuldades de aprendizagem caracteriza uma limitação deste estudo, o que acirra a derivar na necessidade de buscar outras investigações adotando critérios metodológicos diversos para comparar e compreender mais aspectos de funções cognitivas e dificuldades de aprendizagem estudos futuros, quiçá internacionais.

Houve grande concentração de estudos desenvolvidos por fonoaudiólogos e, em secundariamente, por psicólogos. Os demais estudos foram desenvolvidos multiprofissionalmente. Pode-se perceber que a maioria dos estudos relacionou os transtornos e dificuldades de aprendizagem com déficits no processamento da linguagem, tal fato pode ser interpretado como uma possível justificativa para a grande produção por parte de fonoaudiólogos e sua ênfase nas intervenções dos casos acometidos.

Notou-se no decorrer da análise dos estudos a presença massiva de diversos profissionais da área da saúde, porém pouca presença de terapeutas ocupacionais, onde somente um estudo contou com a colaboração do profissional terapeuta ocupacional. Isso chama a atenção para que ajam mais pesquisas na área sendo desenvolvidas por terapeutas ocupacionais com objetivo de auxiliar ainda mais no progresso do desempenho e aprendizagem, que relacionem tais déficits cognitivos à participação ampla em contextos da vida diária e ocupações relevantes aos indivíduos alvos. Em particular tais profissionais, agora citados, são responsáveis pela análise das atividades executadas pelo indivíduo em outros contextos identificando possibilidades de intervenção que apoiem o desenvolvimento de capacidades relativas à aprendizagem. Ressalta-se que houve limitação na busca de artigos internacionais, no escopo metodológico desta revisão, sendo assim a crítica relacionada à escassa participação da área da Terapia Ocupacional nos estudos pode ou não se dever a esse fator.

As funções cognitivas estão interligadas e interdependentes, num funcionamento neuro-cerebral integrativo, o que significa que essa complexidade se deva considerar também na avaliação dos déficits cognitivos em crianças em idade escolar que apresentem dificuldades de aprendizagem, podendo caracterizar quadros específicos de transtornos de aprendizagem. Logo o desempenho acadêmico de crianças com déficits na aprendizagem mostra-se afetado no só no contexto escolar focal, mas também 
possivelmente nos demais contextos em algum nível da participação, pois as capacidades cognitivas ainda que alteradas são necessárias à vida cotidiana. É importante salientar que a delimitação desta revisão tratou de crianças na idade escolar e das complexidades relacionadas à aprendizagem nessa fase, a literatura reportou crianças que possuíam dificuldades em seu desempenho no contexto escolar, assim os resultados foram favoráveis para analisar às alterações cognitivas das crianças apenas em elementos que compõem a vida na escola.

A forte relação entre os transtornos de aprendizagem e déficits em habilidades cognitivas foi observada ao longo de todo o estudo, a qual afeta de maneira significativa de compreender como o desempenho escolar de crianças sofre interferência, o que pode ser observado principalmente no desempenho acadêmica apoiado nas funções da leitura, escrita e assimilação de conteúdos formais na aprendizagem. Nota-se com isso que o desenvolvimento de crianças com déficits de aprendizagem diferencia-se das crianças típicas em determinadas tarefas e atividades escolares, porém alguns artigos apesar de detectarem alterações nas funções cognitivas, apontaram a necessidade de mais investigações na área, utilizando diferentes recursos avaliativos padronizados com objetivo de identificar características mais precisas e sensíveis à diferenciação diagnósticas dos casos complexos abordados.

A relevância desta presente revisão reside na verificação criteriosa das publicações nacionais que caracterizaram intervenções focadas em crianças ditas com dificuldades de aprendizagem, permitindo esclarecer qual quadro complexo de atuações são desenvolvidas no Brasil, cuja ênfase na participação escolar torna-se evidente e característica marcante da preocupação dos pesquisadores envolvidos desde estudos mais remotos aos atuais.

\section{Referências}

Algeri, M. S. (2014). Dificuldades de aprendizagem na escrita: um olhar psicopedagógico. Revista de Educação do IDEAU, 9(20), 1-12. Recuperado de https://www.academia.edu/36773190/DIFICULDADES_DE_APRENDIZAGEM_N A_ESCRITA_um_olhar_psicopedag\%C3\%B3gico

Almeida, L. S. (2002). Facilitar a aprendizagem: ajudar os alunos a aprender a pensar. Psicologia Escolar e Educacional, 6(2), 155-165. doi: 10.1590/S141385572002000200006 
Alves, L. M., Souza, H. T. V., Souza, V. O., Lodi, D. F., Ferreira, M. C. M., Siqueira, C. M., \& Celeste, L. C. (2014). phonological processing in individuals with attention deficit hyperactivity disorder. Revista CEFAC, 16(3), 874-882. doi: 10.1590/1982021620145813

American Psychiatry Association (2013). Diagnostic and Statistical Manual of Mental Disorders - DSM-5. Washington: American Psychiatric Association.

Antunes, L. G., Freire, T., \& Crenitte, P. A. P. (2015). Phonological awareness training in students with risk indicators for learning difficulties. Distúrbios da Comunicação, 25(2), 225-236. Recuperado de https://revistas.pucsp.br/dic/article/view/20049/17893

Byrne, B., \& Barnsley, F. R. (1989). Phonemic awareness and letter knowledge in the child's acquisition of the alphabetic principle. Journal of Educational Psychology. 3(81), 313-321. Recuperado de https://psycnet.apa.org/record/1990-04122-001

Cavalcante, C. H. L., \& Santos, P. A. J. (2013). Fatores que influenciam o desempenho escolar: a percepção dos estudantes do curso técnico em contabilidade do IFRS. Revista Liberato, 14(21), 1-112. doi: 10.31514/rliberato.2013v14n21.p29

Corso, H. V., Sperb, T. M., \& Salles, J. F. (2013). Comparação Entre Maus Compreendedores e Bons Leitores em Tarefas Neuropsicológicas. Psicologia em Pesquisa, 7(1), 37-49. doi: 10.5327/Z1982-1247201300010005

Domingos, G. A. (2009). Dificuldades do processo de aprendizagem. Monografia, Escola Superior Aberta do Brasil, Espírito Santo.

Ferreira, F. O., Wood, G., Chagas, P. P., Lonnemann, J., Krinzinger, H., Willmes, K., \& Haase, V. G. (2012). Explaining school mathematics performance from symbolic and nonsymbolic magnitude processing: similarities and differences between typical and low-achieving children. Psychology \& Neuroscience, 5(1), 37-46. doi: 10.3922/j.psns.2012.1.06

Figueiredo, V. L. M., Quevedo, L., Gomes, G., \& Pappen, L. (2007). Habilidades cognitivas de crianças e adolescentes com distúrbio de aprendizagem. PsicoUSF, 12(2), 281-290. doi: 10.1590/S1413-82712007000200016

Gabriel, R. (2008). Compreensão em leitura enquanto processo cognitivo. Signo, 73-83. doi:10.17058/signo.v31i0.441 
Germano, G. D., \& Capellini, S. A. (2011). Performance of students with dyslexia, learning disabilities and learning difficulties in metaphonological abilities tests (PROHFON). Jornal da Sociedade Brasileira de Fonoaudiologia, 23(2), 135-141. doi: $10.1590 /$ S2179-64912011000200010

Germano, G. D.; Pinheiro, F. H.; \& Capellini, S. A. (2013). Desempenho de escolares com dislexia: programas de intervenção metalinguístico e de leitura. Psicologia Argumento, 31(72), 11-22. doi: 10.7213/psicol.argum.7597

Granzotti, R. B. G. Furlan, S. A., Domenis, D. R., \& Fukuda, M. T. H. (2013). Memória de trabalho fonológica e consciência fonológica em crianças com dificuldade de aprendizagem. Distúrbios da Comunicação, 25(2), 241-252. Recuperado de https://revistas.pucsp.br/dic/article/view/16477/12374

Guimarães, S. R. K. (2002). Dificuldades no Desenvolvimento da Lectoescrita: O Papel das Habilidades Metalinguísticas. Psicologia: Teoria e Pesquisa, 18(3), 247-259. Recuperado de http://www.scielo.br/pdf/\%0D/ptp/v18n3/a03v18n3.pdf

Hemsing, M., \& Skrsypsack, D. (2016). Dificuldades de Aprendizagem. [Resumo]. In $7^{o}$ Seminário de Iniciação Científica do Curso de Pedagogia e $3^{\circ}$ Seminário Institucional Interdisciplinar PIBID (p. 1-11). Santa Catarina: FAI Faculdades.

Kawano, C. E., Kida, A. S. B., Carvalho, C. A. F., \& Ávila, C. R. B. (2011). Parâmetros de fluência e tipos de erros na leitura de escolares com indicação de dificuldades para ler e escrever. Revista da Sociedade Brasileira de Fonoaudiologia, 16(1), 9-18. doi: $10.1590 / \mathrm{S} 1516-8034201100010000$

Kida, A. S. B., Ávila, C. R. B., \& Capellini, S. A. (2015). Syntactic markers in the oral retelling of dyslexic students. CoDAS, 27(6), 557-564. doi: 10.1590/2317$1782 / 20152015106$

Lima, R. F., Azoni, C. A. S., \& Ciasca, S. M. (2011). Attentional performance and executive functions in children with learning difficulties. Psicologia: Reflexão $e$ Crítica, 24(4), 685-691. doi: 10.1590/S0102-79722011000400008 
Martins, C. C., \& Triginelli, M. F. M. (2009). Codificação fonológica e ortográfica na dislexia de desenvolvimento: evidência de um estudo de caso. Arquivos Brasileiros de Psicologia, 61(1), 153-161. Recuperado de http://pepsic.bvsalud.org/scielo.php?script=sci_arttext\&pid=S180952672009000100015

Messina, L. F., \& Tiedemann, K. B. (2009). Avaliação da memória de trabalho em crianças com transtorno do déficit de atenção e hiperatividade. Psicologia USP, 20(2), 209-228. doi: 10.1590/S0103-65642009000200005

Miranda, M. C., Barbosa, T., Muszat, M., Rodrigues, C. C., Sinnes, E. G., Coelho, L. F. S., S., Rizzuti, S., Palma, S. M. M., \& Bueno. O. F. A. (2012). Performance patterns in Conners' CPT among children with attention deficit hyperactivity disorder and dyslexia. Arquivos de Neuro-Psiquiatria, 70(2), 91-96. doi: 10.1590/S0004282X2012000200004

Muszcat, M., \& Mello, C. B. (2009). Neurodesenvolvimento e linguagem. In Barbosa T., Rodrigues, C. C., Mello C. B., Capellini, S. A., Mousinho, R., Alves, L. M. Temas em dislexia (pp. 1-15). São Paulo: Artes Médicas. p. 1-15.

Nicolielo, A. P., Gejão, M. G., Lopes-Herrea, S. A., \& Maximino, L. P. (2014). Evolution of the speech-language therapy in a case report of specific language impairment (SLI). Revista CEFAC, 16(5), 1691-1699. doi: 10.1590/1982-0216201423312

Nunes, C., Frota, S., \& Mousinho, R. (2009). Consciência fonológica e o processo de aprendizagem de leitura e escrita: implicações teóricas para o embasamento da prática fonoaudiológica. Revista CEFAC, 11(2), 207-212. doi: 10.1590/S151618462009000200005

Okuda, P. M. M., Pinheiro, F. H., Germano, G. D., Padula, N. A. M. R., Lourencetti, M. D., Santos, L. C. A., \& Capellini, S. A. (2011). Fine motor, sensory and perceptive function of students with attention deficit disorder with hyperactivity. Jornal da Sociedade Brasileira de Fonoaudiologia, 23(4), 351-357. doi:10.1590/S217964912011000400010 
Oliveira, A. M., Cardoso, M. H., Padula, N. A. M. R., Lourencetti, M. D., Santos, L. C. A., \& Capellini, S. A. (2013). Processos de leitura em escolares com Transtorno de Deficit de Atenção/Hiperatividade. Psicol. Argumento, 31(72), 35-44. doi: 10.7213/psicol.argum. 7580

Oliveira, A. M., Germano, G. D., \& Capellini, S. A. (2015). Desempenho de escolares com dificuldades de aprendizagem em programa computadorizado de intervenção metafonológica e leitura. Psicologia Argumento, 33(80), 226-241. doi: 10.7213/psicol.argum.33.080.AO01

O. M. P. R., \& Melchiori, L. E. (2014). Aspectos do desenvolvimento na idade escolar e na adolescência. São Paulo: UNESP Recuperado de https://acervodigital.unesp.br/bitstream/unesp/155338/3/unespnead_reei1_ee d06_s01_texto01.pdf

Piaget, J. (1972). Development and learning. In Lavatelly, C. S. \& Stendler, F. Reading in child behavior and development (pp. 7-19). New York: Hartcourt Brace Janovich.

Salles, J. F., \& Parente, M. A. M. P. (2008). Variabilidade no desempenho em tarefas neuropsicológicas entre crianças de $2^{\mathrm{a}}$ série com dificuldades de leitura e escrita. Arquivos Brasileiros de Psicologia, 60(1), 32-44. Recuperado de http://pepsic.bvsalud.org/scielo.php?script=sci_arttext\&pid=S180952672008000100004

Santos, N. M. (2009). Problematização das dificuldades de aprendizagem. Trabalho de conclusão das atividades do Programa de Desenvolvimento Educacional - PDE, Universidade Estadual de Londrina, Londrina.

Silva, A. P. C., \& Capellini, S. A. (2011). Phonological remediation program in students with learning difficulties. Jornal da Sociedade Brasileira de Fonoaudiologia, 23(1), 13-20. doi: 10.1590/S2179-64912011000100006

Silva, C., Cunha, V. L. O., \& Capellini, S. A. (2011). Performance cognitive-linguistic and reading of students with attention deficit and hyperactivity disorder. Revista brasileira de crescimento e desenvolvimento humano, 21(3), 849-858. Recuperado de http://pepsic.bvsalud.org/scielo.php?script=sci_arttext\&pid=S010412822011000300011 
Silva, C., \& Capellini, S. A. (2011). Correlation between time, error, speed and reading comprehension in students with learning disorders. Revista da Sociedade Brasileira de Fonoaudiologia, 16(4), 412-416. doi: 10.1590/S1516-80342011000400008

Silva, C., \& Capellini, S. A. (2013) Desempenho de escolares com e sem transtorno de aprendizagem em leitura, escrita, consciência fonológica, velocidade de processamento e memória de trabalho fonológica. Revista Psicopedagogia, 30(91), 311. Recuperado de http://pepsic.bvsalud.org/scielo.php?script=sci_arttext\&pid=S010384862013000100002

Silva, P. A., Ribeiro, F. S., \& Santos, F. H. (2015). Cognição Numérica em Crianças com Transtornos Específicos de Aprendizagem. Temas em Psicologia, 23(1), 197-210. doi: 10.9788/TP2015.1-13

Soares, A. J. C., Sanches, S. G. G., Alves, D. C., Carvallo, R. M. M., \& Cárnio, M. S. (2013). Processamento temporal e consciência fonológica nas alterações de leitura e escrita: dados preliminares. CoDAS, 25(2), 188-190. doi: 10.1590/S231717822013000200016 